\title{
TORSION TESTS FOR FEMORAL, HUMERAL AND TIBIAL NAILS
}

\author{
K. Frydrýšek*, V. Machalla** F. Fojtík ${ }^{* * *}$, L. Pleva ${ }^{\dagger}$
}

\begin{abstract}
This article represents a multidisciplinary approach to biomechanics in the field of femoral, humeral and tibial intramedullary nails made of Ti6Al4V or stainless steel. This paper therefore aims to offer our proposed experimental solution (i.e. torsion test) of femoral nails together with their possible assessment. During the solution, the fixation effects were considered in the jaws of a laboratory test machine and elastic and plastic strains (yield limits, maximum torque etc.)
\end{abstract}

Keywords: torsion, femoral nail, humeral nail, tibial nail, experiments, plasticity

\section{Introduction}

Femoral, humeral and tibial fractures always remain a vexing clinical problem in traumatology and orthopaedics and are one of the most common types of trauma, especially amongst elderly patients; for example, see Fig. 1 and references (Hoza et al 2008) and (Čada et al 2017). For example, as a consequence, femoral fractures are a significant cause of morbidity and mortality in all age groups. Thererefore, it is important to deal with it. One possible treatment method (osteosynthesis) for the femoral, tibial and humeral fractures, is the application of intramedullary nails; see Fig. 1.
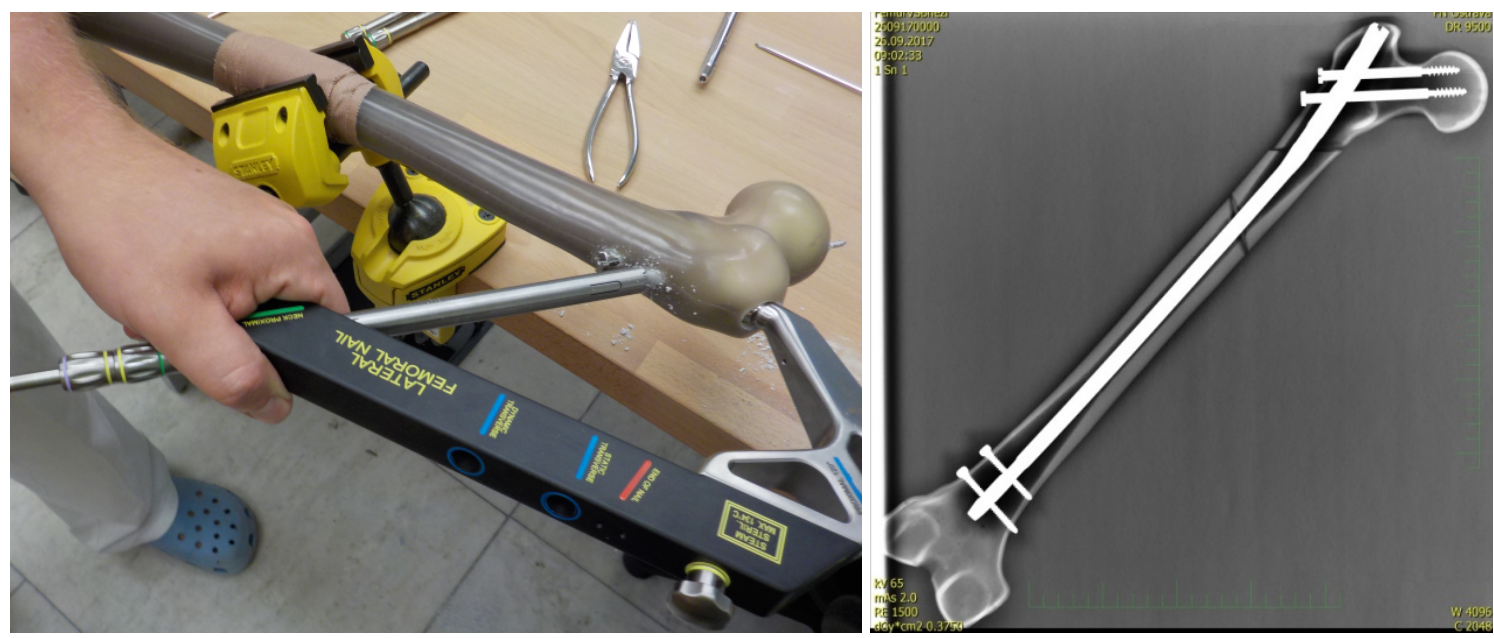

Fig. 1: (a) Application of femoral nail into artificial femur; (b) Rtg. snapshot of artificial femoral bone with subtrochanteric facture and femoral nail.

Assoc. Prof. Karel Frydrýšek, PhD., ING-PAED IGIP, VSB - Technical University of Ostrava, Faculty of Mechanical Engineering, Department of Applied Mechanics, 17. listopadu 15/2172, 70833 Ostrava, CZ, karel.frydrysek@vsb.cz

** MSc. Vojtěch Machalla, VSB - Technical University of Ostrava, Faculty of Mechanical Engineering, Department of Applied Mechanics, 17. listopadu 15/2172, 70833 Ostrava, CZ, vojtech.machalla@vsb.cz

*** MSc. František Fojtík, PhD., VSB - Technical University of Ostrava, Faculty of Mechanical Engineering, Department of Applied Mechanics, 17. listopadu 15/2172, 70833 Ostrava, CZ, frantisek.fojtik@vsb.cz

$\dagger \quad$ Assoc. Prof. M.D. Leopold Pleva, Ph.D., Trauma Centre, University Hospital Ostrava, 17. listopadu 1790, 708 52, Ostrava, CZ \& Institute of Emergency Medicine, Faculty of Medicine, University of Ostrava, Syllabova 19, 70300 Ostrava, CZ, leopold.pleva@fno.cz 
However, the laboratory tests of biomechanical materials, such as torsion test (according ASTM F1264) are important for evaluation and future development of femoral, tibial and humeral nails.

\section{Torsion tests of femoral, tibial and humeral nails}

According to ASTM F1264 standard, the torsion tests were performed for femoral, tibial and humeral nails in the laboratories at the Department of Applied Mechanics (Faculty of Mechanical Engineering, VSB - Technical University of Ostrava, Ostrava, Czech Republic).

Reference (Frydrýšek et al 2002) describes in detail our new original torsion test evaluation method (i.e. Fuxa's method) and its refinement for a quasi-static and proportionally loaded symmetric specimen, for example see Fig. 2. This method holds for elasto-plastic domain and large deformations. Thus, for the equivalent plastic strain $S_{\varepsilon p} / 1 /$ holds the followed equation

$$
S_{\varepsilon p}=f(r, \varphi, \mathrm{L})=\frac{1}{\sqrt{3}} \ln \left(\frac{2+\frac{r^{2} \varphi^{2}}{2 \mathrm{~L}^{2}}+\frac{r \varphi}{\mathrm{L}} \sqrt{\frac{r^{2} \varphi^{2}}{4 \mathrm{~L}^{2}}+1}}{2+\frac{r^{2} \varphi^{2}}{2 \mathrm{~L}^{2}}-\frac{r \varphi}{\mathrm{L}} \sqrt{\frac{r^{2} \varphi^{2}}{4 \mathrm{~L}^{2}}+1}}\right),
$$

where $r / \mathrm{mm} /$ is the diameter and $\mathrm{L} / \mathrm{mm} /$ is the active length of steel specimen and $\varphi=f($ time $) / \mathrm{rad} /$ is a twisting angle (time-changing values), see Fig. 2 and 3.
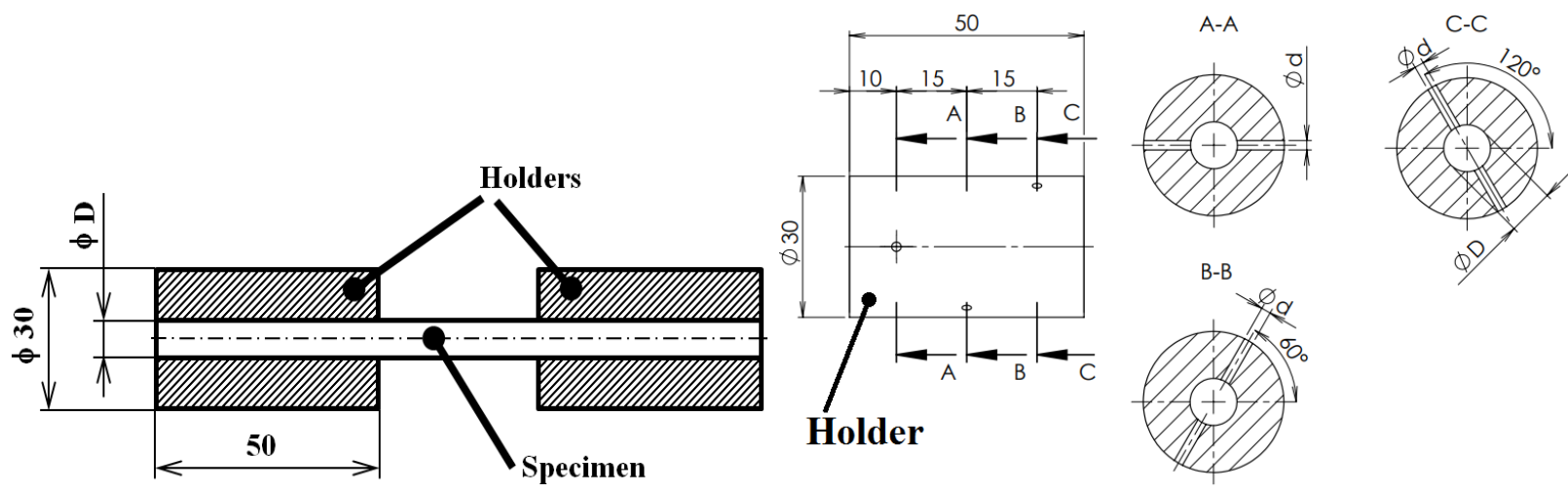

Fig. 2: (a) Diagram of the laboratory specimen with glued and coupled holders (Loctite 638 glue was applied); (b) Holder with holes for couplings.

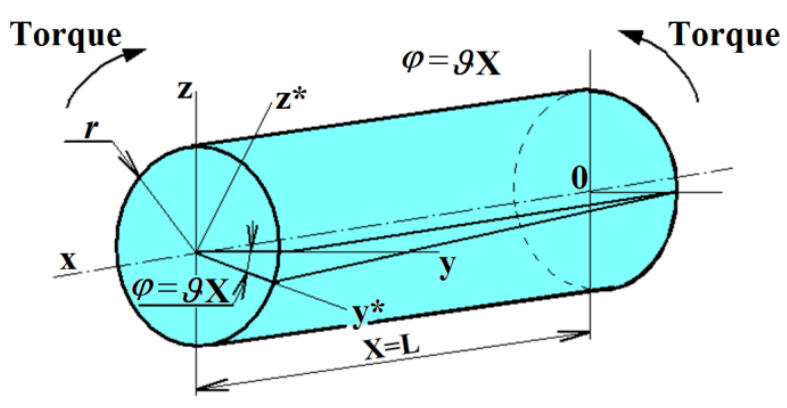

Fig. 3 The basic parameters for torsion tests.

There were performed 16 torsion tests of nail specimens on biaxial pulsator ZUZ 100 (INSTRON producer), see Fig. 4.

Derivations and applications of eq. (1) are presented in (Frydrýšek et al 2002). However, in scientific literature, there is a lack of information about torsion test evaluation (i.e. usually, tensile tests of materials are preferred). But good tests are important for reliability assessments according to ASTM F1264 standard in subsequent connection with medical applications.

Laboratory specimens were made up from Ti 6Al 4V ELI and stainless steel 1.4441. 


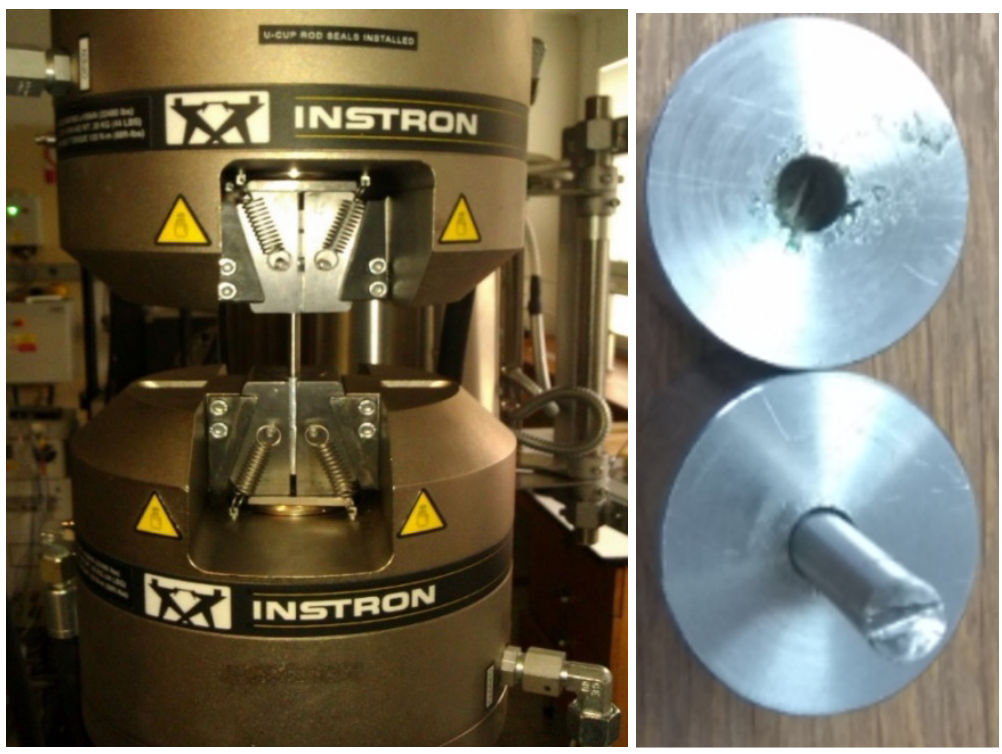

Fig. 4 Measurements and fracture of specimen.

\section{Results}

Some examples of measurements are presented on Fig. 5 and 6 and Tab. 1. (i.e. torque - twisting angle \& torque - equivalent plastic strain dependencies). The first parts of dependencies (curves) are nearly linear (i.e. elasticity, ended by yield limit) and the second parts of dependencies are nonlinear (i.e. elastoplasticity) which are typical material behaviours.

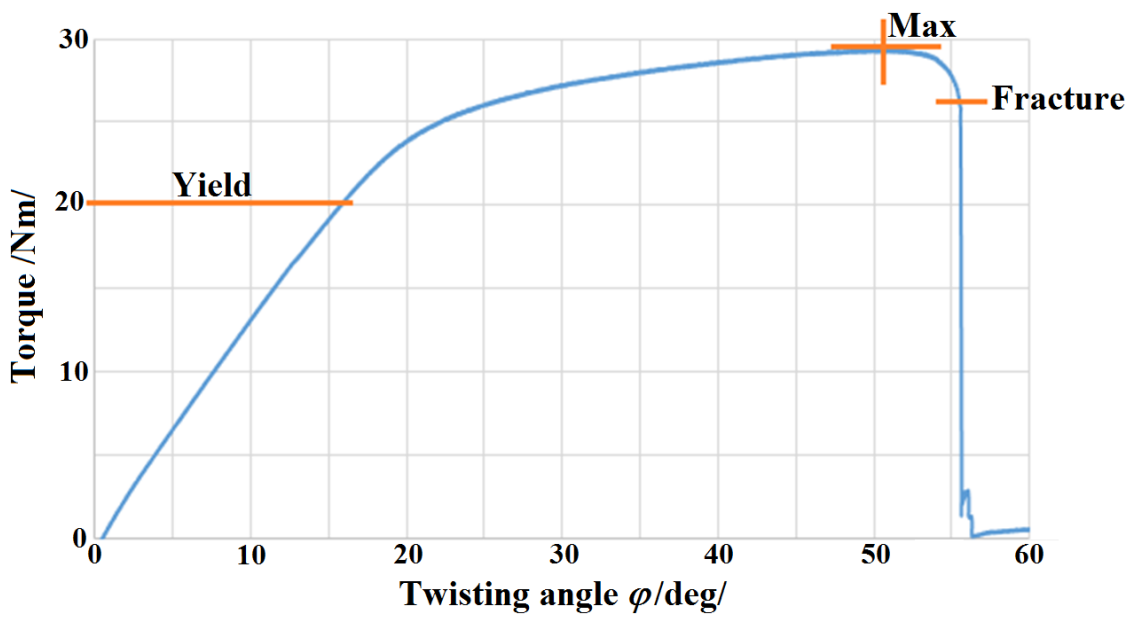

Fig. 5 Measurement 15 -Dependence of Torque on Twisting angle.

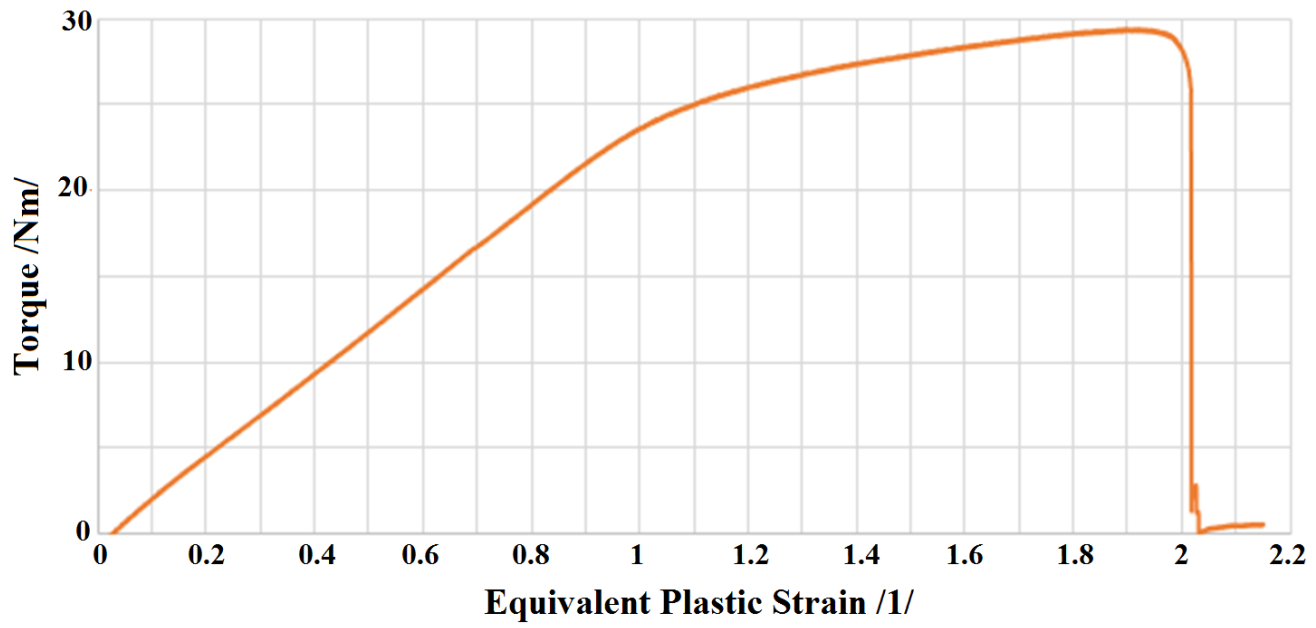

Fig. 6 Measurement 15 - Dependence of Torque on Equivalent plastic strain. 
Tab. 1 List of basic results (Torsion test of material for femoral, humeral and tibial intramedullary nails)

\begin{tabular}{|c|c|c|c|c|}
\hline \multirow{2}{*}{ Measurement: } & \multicolumn{2}{|c|}{ Specimen Specification } & \multirow{2}{*}{ Max. Torque / Nm/ } & \multirow{2}{*}{ Yield Torque /Nm } \\
\hline & $\mathrm{D} / \mathbf{m m} /$ & Material & & \\
\hline 1. & 10.55 & \multirow{4}{*}{ Ti 6A1 4V ELI } & 150 & 100 \\
\hline 2. & 10.55 & & 147 & 100 \\
\hline 3. & 10.54 & & 150 & 100 \\
\hline 4. & 10.56 & & 152 & 100 \\
\hline 5. & 9.99 & \multirow{12}{*}{1.4441 (stainless) } & 128 & 90 \\
\hline 6. & 9.98 & & 127 & 90 \\
\hline 7. & 9.99 & & 127 & 90 \\
\hline 8. & 9.98 & & 128 & 90 \\
\hline 9. & 9.98 & & 129 & 90 \\
\hline 10. & 9.99 & & 126 & 90 \\
\hline 11. & 9.00 & & 93 & 60 \\
\hline 12. & 8.96 & & 92 & 60 \\
\hline 13. & 8.95 & & 85 & 60 \\
\hline 14. & 6.01 & & 29 & 20 \\
\hline 15. & 6.00 & & 29 & 20 \\
\hline 16. & 5.99 & & 29 & 20 \\
\hline
\end{tabular}

\section{Conclusion}

Complicated fractures represent an important therapeutic problem and therefore it is important to deal with it.

The laboratory torsion tests of 16 material specimens of femoral, humeral and tibial intramedullary nails were performed together with consideration of fixation effects in testing machines, see Tab. 1 (dimensions, material, maximal torque, yield torque etc.). Evaluation method for torsion tests was developed at Department of Applied Mechanics (FME, VSB - Technical University of Ostrava) and subsequently applied according to ASTM F1264 standard.

Performing these tests along with some other material tests can provide the basic information about material behaviour suitable for producing femoral, humeral and tibial intramedullary nails applied in traumatology/orthopaedics. According to the results, the verifications of these intramedullary nails are sufficient. Therefore, these nails can be used for treatment of patients and will satisfy the ambitious demands of modern science (i.e. applications in traumatology/orthopaedics).

Future research will focus on fatigue testing or FEM modelling, similarly as published in reference Frydrýšek (2017), i.e. stochastic evaluation.

\section{Acknowledgement}

The authors gratefully acknowledge the funding from the Czech projects TA03010804 and SP2018/63.

\section{References}

Čada, R., Frydrýšek, K., Sejda, F. et al. (2017) Analysis of Locking Self-Taping Bone Screws for Angularly Stable Plates, J. Med. Biol. Eng. 37: pp. 612-625, ISSN 2199-475, https://doi.org/10.1007/s40846-017-0279-4

Frydrýšek, K., Fusek, M., Fuxa, J. (2002) Torsion Tests for Steel Specimens and their Numerical and Experimental Evaluation, In: Engineering Mechanics 2002, Brno University of Technology, Brno, pp.55-56, (full version on CD).

Frydrýšek, K. (2017) The Probabilistic Approach and its Practical Applications in Medical and Mechanical Engineering, in book: Walls, L., Revie, M. and Bedford, T. (eds) Risk, Reliability and Safety: Innovating Theory and Practice, CRC Press-Taylor \& Francis Group, Glasgow, pp. 2453-2460, ISBN:978-1-315-37498-7.

Hoza, P., Hála, T. and Pilný J. (2008) Fractures of Proximal Femur and their Solution, (Zlomeniny proximálního femuru a jejich řešení), Medicína pro praxi, 2008, 10 (5), ISSN 1214-8687, pp. 393-397 